\title{
The novel miR-9500 regulates the proliferation and migration of human lung cancer cells by targeting Akt1
}

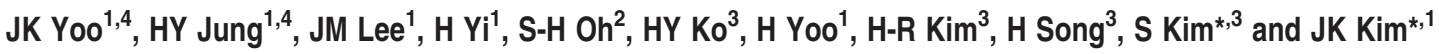

\begin{abstract}
MicroRNAs have crucial roles in lung cancer cell development. They regulate cell growth, proliferation and migration by mediating the expression of tumor suppressor genes and oncogenes. We identified and characterized the novel miR-9500 in human lung cancer cells. The miR-9500 forms a stem-loop structure and is conserved in other mammals. The expression levels of miR-9500 were reduced in lung cancer cells and lung cancer tissues compared with normal tissues, as verified by TaqMan miRNA assays. It was confirmed that the putative target gene, Akt1, was directly suppressed by miR-9500, as demonstrated by a luciferase reporter assay. The miR-9500 significantly repressed the protein expression levels of Akt1, as demonstrated via western blot, but did not affect the corresponding mRNA levels. Akt1 has an important role in lung carcinogenesis, and depletion of Akt1 has been shown to have antiproliferative and anti-migratory effects in previous studies. In the current study, the overexpression of miR-9500 inhibited cell proliferation and the expression of cell cycle-related proteins. Likewise, the overexpression of miR-9500 impeded cell migration in human lung cancer cells. In an in vivo assay, miR-9500 significantly suppressed Fluc expression compared with NC and ASO-miR-9500, suggesting that cell proliferation was inhibited in nude mice. Likewise, miR-9500 repressed tumorigenesis and metastasis by targeting Akt1. These data indicate that miR-9500 might be applicable for lung cancer therapy.
\end{abstract}

Cell Death and Differentiation (2014) 21, 1150-1159; doi:10.1038/cdd.2014.33; published online 21 March 2014

MicroRNAs (miRNAs) are small, non-coding RNAs, 18-25 nucleotides (nt) in length that regulate gene expression by binding to the $3^{\prime}$-untranslated region (UTR) of their target genes, ${ }^{1,2}$ and these RNAs are processed from introns, exons or intergenic regions. ${ }^{3}$ First, miRNAs are transcribed by RNA polymerase II into primary miRNA (pri-miRNA) molecules that contain several thousand nucleotides. The pri-miRNAs are then sequentially processed by a microprocessor, such as Drosha RNase III endonuclease and DiGeorge syndrome region gene 8 protein (DGCR8), to form $\sim 70$ nt-stem-loop intermediates known as miRNA precursors (pre-miRNAs). ${ }^{4,5}$ The pre-miRNAs are then exported from the nucleus into the cytoplasm via Exportin-5 (EXP5), with its cofactor Ran-GTP; in the cytoplasm, these pre-miRNAs are processed into 18-25 nt mature miRNA duplexes by the RNase III endonuclease Dicer. ${ }^{6,7}$ The mature miRNA duplexes, along with the Argonaute proteins, are integrated as single-stranded RNAs into an RNA-induced silencing complex, which induces either the cleavage or the translational inhibition of the targeted mRNAs. ${ }^{8-10}$ miRNAs have been implicated in a variety of biological processes associated with cancer development, including cell proliferation and invasion, ${ }^{11}$ and miRNA expression is deregulated in many forms of cancer. ${ }^{12}$
Cancer is a major public health problem worldwide. Lung cancer represents one of the most predominant types of cancer, with high mortality rates in both men and women. Epithelial lung cancer can be categorized into one of two types: small cell lung cancer (SCLC) or non-small cell lung cancer (NSCLC). NSCLC accounts for $\sim 80 \%$ of lung cancer cases, and these cases can be further categorized as adenocarcinoma (40\%), squamous cell carcinoma (30-35\%), and large cell carcinoma (5-15\%). NSCLC has a 5-year survival rate of only $16 \%$. $^{13-15}$ Current studies have shown that miRNAs are deregulated in various cancers, including NSCLC, and may act as oncogenes or tumor suppressor genes. ${ }^{16}$ For example, the Let-7 family, ${ }^{17} \mathrm{miR}-15 \mathrm{a} / 16,{ }^{18} \mathrm{miR}-17-92,{ }^{19} \mathrm{miR}-107$ and miR-185, ${ }^{20}$ are deregulated in lung cancer.

Some studies have reported that phosphatidylinositol 3-kinase (PI3K) signaling is activated in human cancers ${ }^{21,22}$ and has an important role in the progression of NSCLC. The PI3K pathway modulates several cellular mechanisms, such as cell survival, proliferation, migration and motility, and thereby significantly affects the growth of tumors. ${ }^{23,24}$ The primary regulator of the PI3K pathway is $A k t$, a protein kinase $\mathrm{B}$ that mediates cell survival, cell death, ${ }^{25}$ cell growth, cell migration and angiogenesis. ${ }^{26-28}$ The silencing of the Akt1

${ }^{1}$ Department of Pharmacy, College of Pharmacy, CHA University, Yatap-dong, Bundang-gu, Seongnam-si, Gyeonggi-do, Republic of Korea; ${ }^{2}$ Department of Neurology, CHA Bundang Medical Center, CHA University, Seongnam-si, Gyeonggi-do, Republic of Korea and ${ }^{3}$ Department of Biomedical Science, College of Life Science, CHA University, 605-21, Yeoksam1-dong, Gangnam-gu, Seoul, Republic of Korea

*Corresponding author: JK Kim, Department of Pharmacy, College of Pharmacy, CHA University, Yatap-dong, Bundang-gu, Seongnam-si, Gyeonggi-do 463-836, Republic of Korea. Tel: +82 31725 8394; Fax: +82 31725 8350; E-mail: kyeoung66@ hanmail.net

or S Kim, Department of Biomedical Science, College of Life Science, CHA University, 605-21, Yeoksam1-dong, Gangnam-gu, Seoul 135-907, Republic of Korea. Tel: +82 2555 5063; Fax: +82 23468 3373; E-mail: kimsoonhag@empal.com

${ }^{4}$ These authors contributed equally to this work.

Abbreviations: miRNA, microRNA; UTR, untranslated region; pri-miRNA, primary miRNA; DGCR8, DiGeorge syndrome region gene 8 protein; pre-miRNA, precursor miRNA; EXP5, Exportin-5; SCLC, small cell lung cancer; NSCLC, non-small cell lung cancer; PI3K, phosphatidylinositol 3-kinase; p-AKT, phosphorylated-AKT; $\mathrm{p}-\mathrm{Rb}$, phosphorylated-Rb; Fluc, firefly luciferase; ASO, antisense oligonucleodie

Received 30.6.13; revised 29.11.13; accepted 12.12.13; Edited by S Piccolo; published online 21.3.14 
gene has been shown to inhibit the proliferation of gastric cancer cells both in vitro and in vivo. ${ }^{29}$ Other studies have shown that aberrant AKT activation has a critical role in tumorigenesis. ${ }^{30}$

In this study, we identified small RNAs in lung cancer cells. To analyze a novel miRNA signature, we examined the structure and sequence of the small RNAs, analyzed the expression patterns of the novel miRNAs in lung cancer tissues and assessed the miRNA target genes. Our data revealed that miR-9500 regulates certain human lung cancer cell functions, including cell growth, proliferation, and migration.

\section{Results}

Discovery of the novel miRNA, miR-9500, in lung cancer cells. In this study, we aimed to identify and characterize novel miRNAs expressed in lung cancer cell lines. To examine the profiles of the novel miRNAs, we analyzed the sequences using the NCBI Basic Local Alignment Search Tool and confirmed the secondary structure formations using the RNAfold program (http://rna.tbi.univie.ac.at/cgi-bin/ RNAfold.cgi) (Figure 1a). The miR-9500 is encoded by a gene located on chromosome 2q35 (219687815-219687833) and is located in the intergenic region between the CYP27A1 and WNT6 genes. The mature miRNA sequence is 5'-AAGGGAAGAUGGUGACCAC-3'. The miR-9500 is conserved in other mammals, such as orangutan, chimpanzee, and monkey (Figure 1b).

The miR-9500 expression is downregulated in lung cancer. To confirm the biological function of miR-9500 in lung cancer cells, we examined the expression profiles of miR-9500 in several lung cell lines, including WI-38, WI-38 VA-13, A549, HCC-1588, and NCl-H596, using TaqMan miRNA assays. According to the results, miR-9500 displayed significantly lower expression levels in the WI-38 VA-13,
A549, HCC-1588, and NCl-H596 cells compared with the WI38 cells. Moreover, miR-9500 was significantly downregulated in the A549 cell line (Figure 2a). We also analyzed the miR9500 expression levels (via TaqMan miRNA assay) in paired tissue samples derived from lung cancer patients. These paired tissue samples included 15 human lung cancer tissues and 15 normal human lung tissues that were obtained from the same patients. As shown in Figure $2 \mathrm{~b}$, the miR-9500 expression levels were downregulated in the lung cancer tissue samples compared with the normal lung tissue samples.

Akt1 is a direct target of miR-9500. On the basis of previous data, the predicted target genes were upregulated in lung cancer because miR-9500 expression was downregulated. We identified the upregulated genes in the lung cancer cell lines using the following web site: http:// www.ebi.ac.uk/gxa/E-MTAB-37. We confirmed whether the predicted target genes had putative miR-9500-binding sites within the $3^{\prime}$-UTR. Akt1, a member of the subfamily of serine/ threonine protein kinases, was selected as a potential target gene of miR-9500, as we found that the miRNA directly bound to the $3^{\prime}$-UTR of $A k t 1$ using a dual luciferase reporter assay in A549 cells. To test the Akt1 putative binding site, we generated a mutant $A k t 1$ construct, Akt1-mut, in which the $3^{\prime}$-UTR of $A k t 1$ was altered using a site-directed mutagenesis kit. As shown in Figure 3a, miR-9500 significantly regulated the luciferase activity of the Akt1 construct, whereas luciferase activity was not generated from the mutant construct. These results indicate that miR-9500 may regulate Akt1 expression by targeting its $3^{\prime}$-UTR.

In addition, quantitative real-time PCR and western blot analyses performed showed that miR-9500 potentially affected the mRNA and protein levels of Akt1 (Figures 3b and c). The negative control (NC), the miR-9500 mimic, ASOmiR-9500, and si-Akt1 were transfected into A549 cells. The overexpression of miR-9500 failed to affect the expression of

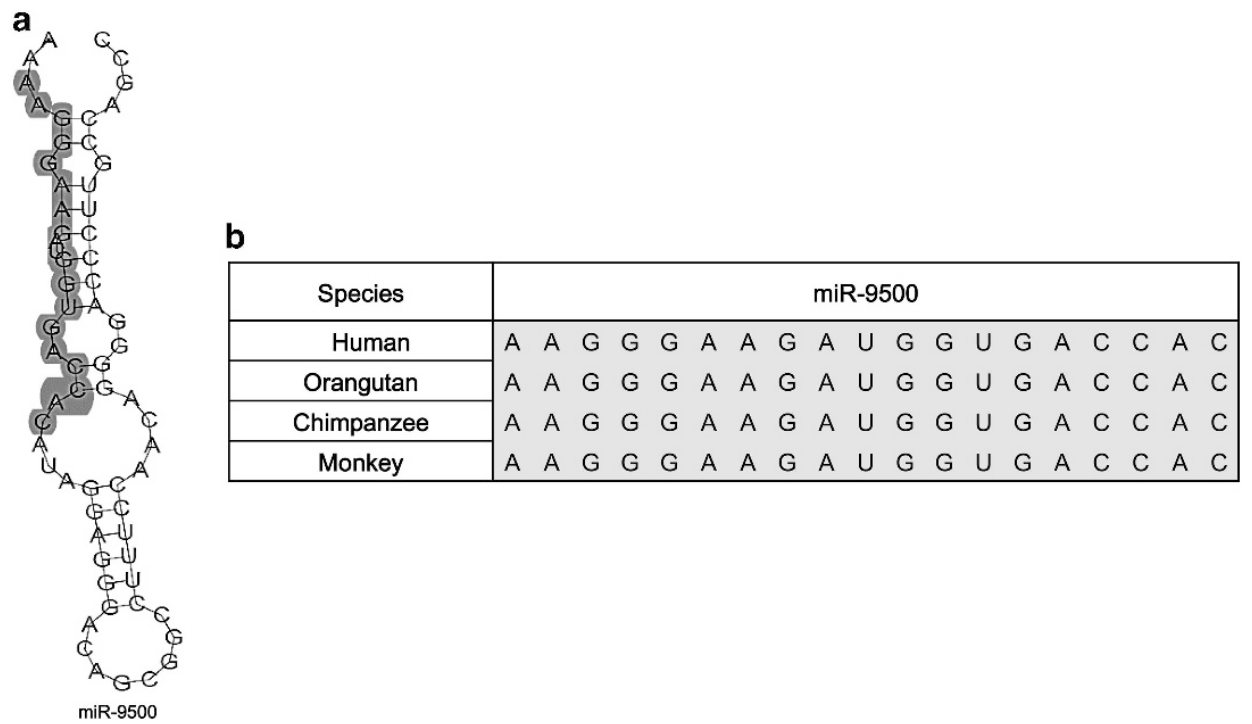

Figure 1 Basic information regarding the novel miR-9500. (a) The predicted secondary structure of the miR-9500 miRNA. Human genomic sequences were examined using the web-based program RNAfold. The mature miR-9500 sequences are marked in gray. (b) The conservation of miR-9500 in other mammals. The conservation results were confirmed using the NCBI BLAST tool 


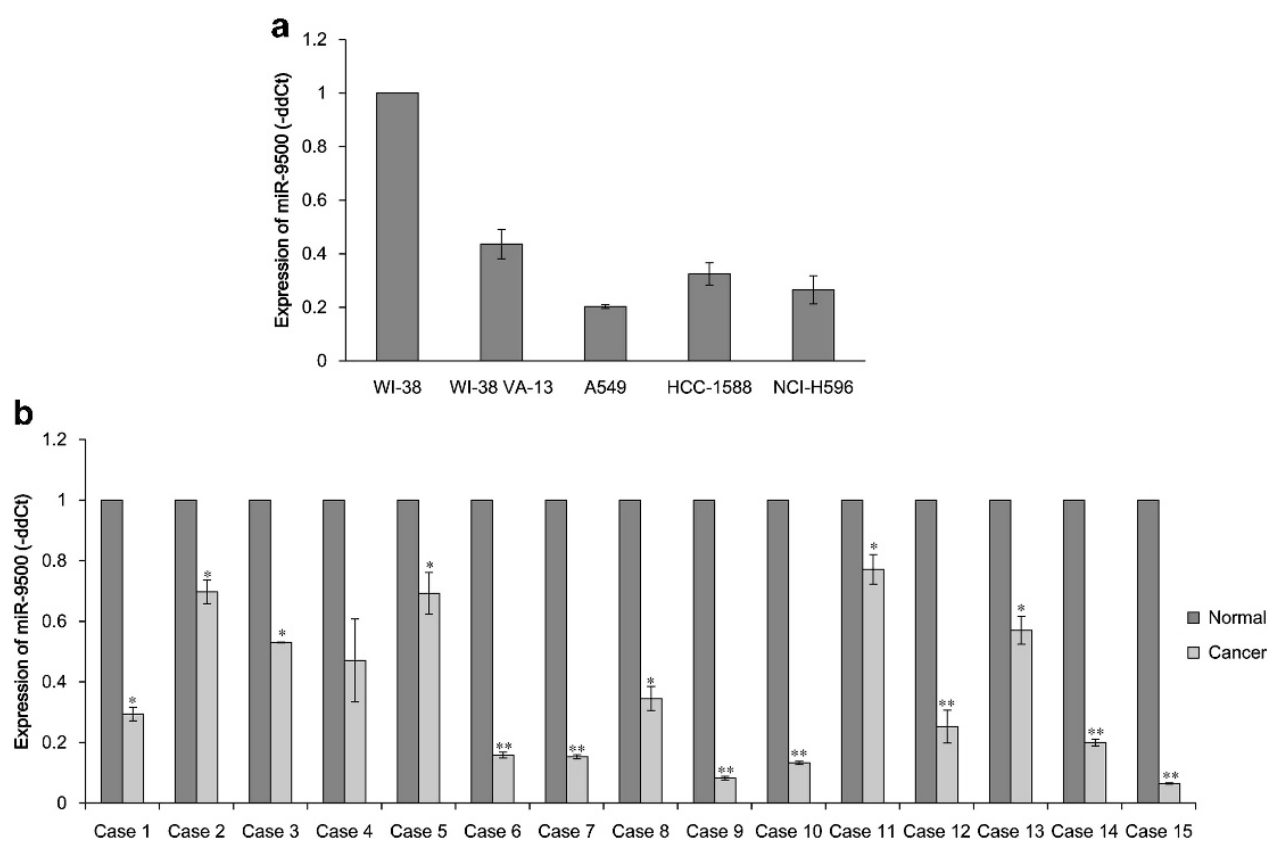

Figure 2 The expression of miR-9500 is downregulated in lung cancer cells and tissues. (a) The miR-9500 expression levels in WI-38, WI-38VA-13, A549, HCC-1588, and $\mathrm{NCl}-\mathrm{H} 596$ cells were analyzed using TaqMan miRNA assays. (b) The expression of miR-9500 was assessed in both lung cancer tissues and normal tissues from lung cancer patients. The expression data were normalized to RNU48. The data are the average of three independent experiments and are shown as the mean \pm S.E.M.; ${ }^{*} P<0.05$ and ${ }^{* \star} P<0.001$

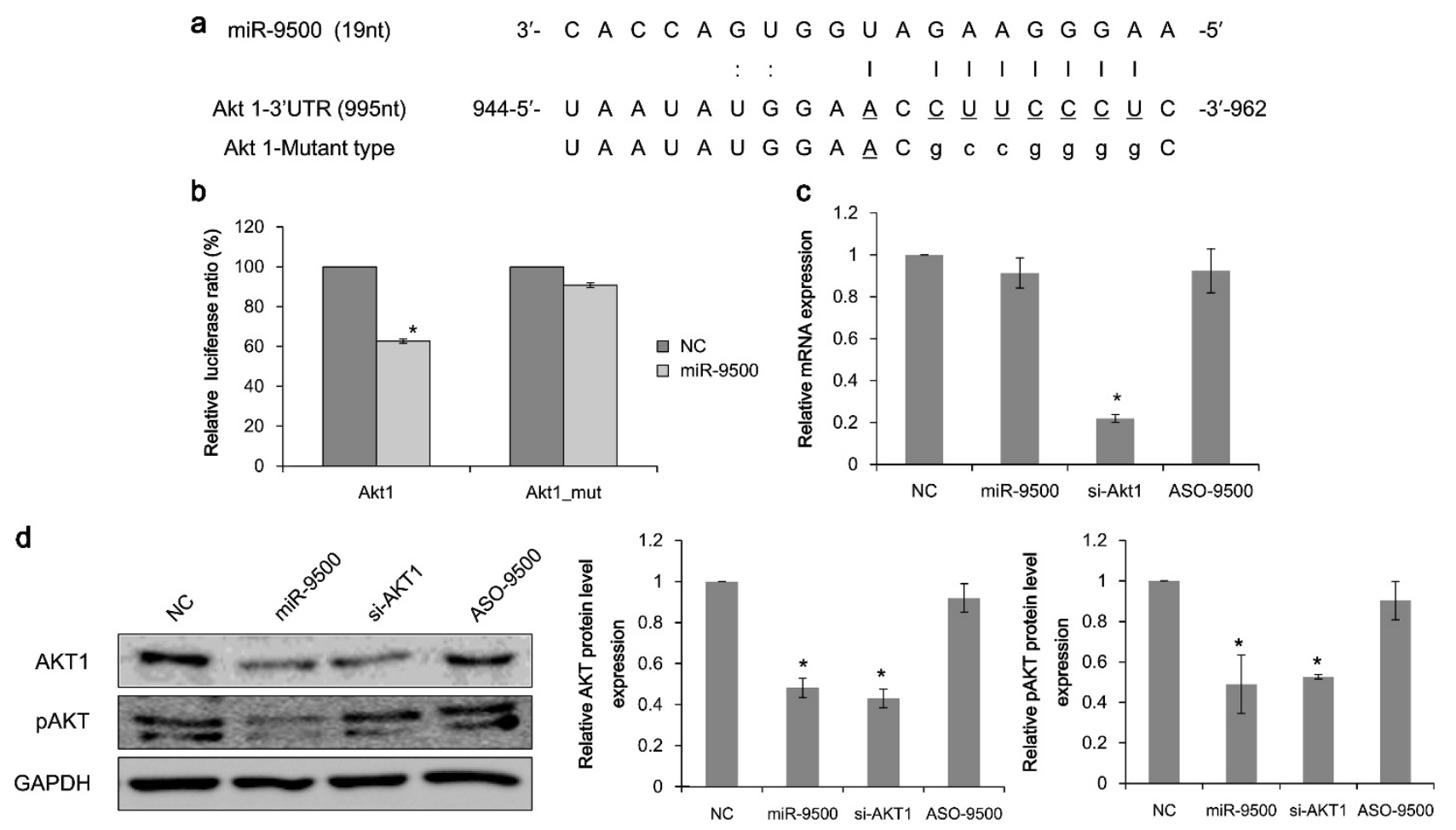

Figure 3 The miR-9500 directly regulates Akt1 expression by targeting the $3^{\prime}$-UTR of Akt1. (a) The binding site (underlined) of miR-9500 in the predicted target sequence. The miR-9500-binding site in the $3^{\prime}$-UTR of the Akt 1 mRNA is displayed. A mutation was generated (small letters) in the Akt1-3'-UTR sequence, which included the seed region of miR-9500. (b) Luciferase activity was analyzed after co-transfection with either miR-9500 or the negative control with the pGL4-Akt1 wild-type plasmid, mutant plasmid, or pGL3-control vector in A549 cells. (c) Total RNA was extracted, and the mRNA levels of Akt1 were analyzed using quantitative RT-PCR analysis. The relative mRNA expression levels were normalized to GAPDH. (d) The AKT1 protein levels were examined using western blot analysis following treatment with the A549-transfected mimics (negative control, miR-9500), Akt1 siRNA, or the ASO-miR-9500. Quantification of the bands was performed using the NIH Image J program, and GAPDH was used as a loading control. The data are the average of three independent experiments and are shown as the mean \pm S.E.M.; ${ }^{*} P<0.05$ 
Akt1 at the mRNA level, whereas AKT1 protein expression was significantly decreased in the miR-9500-transfected cells compared with the control groups (NC and ASO-miR-9500transfected cells). We also confirmed that the expression levels of phosphorylated-AKT (p-AKT) were reduced in the miRNA-transfected cells. All together, these results suggest that miR-9500 directly regulates the protein expression of AKT1 by interacting with its $3^{\prime}$-UTR.

The miR-9500 represses the proliferation of A549 cells. To assess whether miR-9500 inhibits the proliferation of A549 cells, we performed trypan blue staining as well as an XTT assay (Figures $4 a$ and b). The overexpression of miR-9500 significantly suppressed cellular proliferation for $48 \mathrm{~h}$, and a similar pattern was observed after the cells were transfected with si-Akt1 compared with cells transfected with the NC. This result indicates that miR-9500 suppressed cellular proliferation by regulating the expression of AKT1. In addition, we assessed the expression of the downstream genes in the Akt signaling pathway that are associated with the cell cycle (Figure 4c). In the case of miR-9500, this sequence did not match the seed site of the Akt1 signaling genes. We co-transfected the mimic and the inhibitor of miR-9500 into A549 cells and analyzed cell proliferation using an XTT assay (Supplementary Figure 1). The inhibition of AKT1 by miR-9500 significantly decreased the expression levels of phosphorylated-Rb ( $p-R b)$, cyclin $E$, and total CDK2 protein. These data suggest that miR-9500 may regulate cell proliferation by inhibiting AKT1 expression in A549 cells. We performed cell cycle analysis using flow cytometry, and we found that miR-9500 suppressed the G1/S transition and increased the number of cells in the G1 phase compared with the other transfected cells. Likewise, miR-9500 increased the number of cells in the G1 phase by $12 \%$ but decreased the number of cells in the S and G2/M phases by 30 and $40 \%$, respectively (Supplementary Figure 2).

miR-9500 inhibits the migration of A549 cells. Cell motility and migration are key features of cancer development. Therefore, we examined the effect of miR-9500 on cell migration in A549 cells. As shown in Figures 5a and b, A549 cells transfected with miR-9500, si-Akt1, ASO-miR-9500, and NC were assessed via wound healing and Transwell migration assays. These results show that miR-9500 and si-Akt1 suppressed cell motility and migration compared with the NC or ASO-miR-9500, and treatment with miR-9500 and si-Akt1 approximately repressed $40-50 \%$ of the cells' migratory activity.
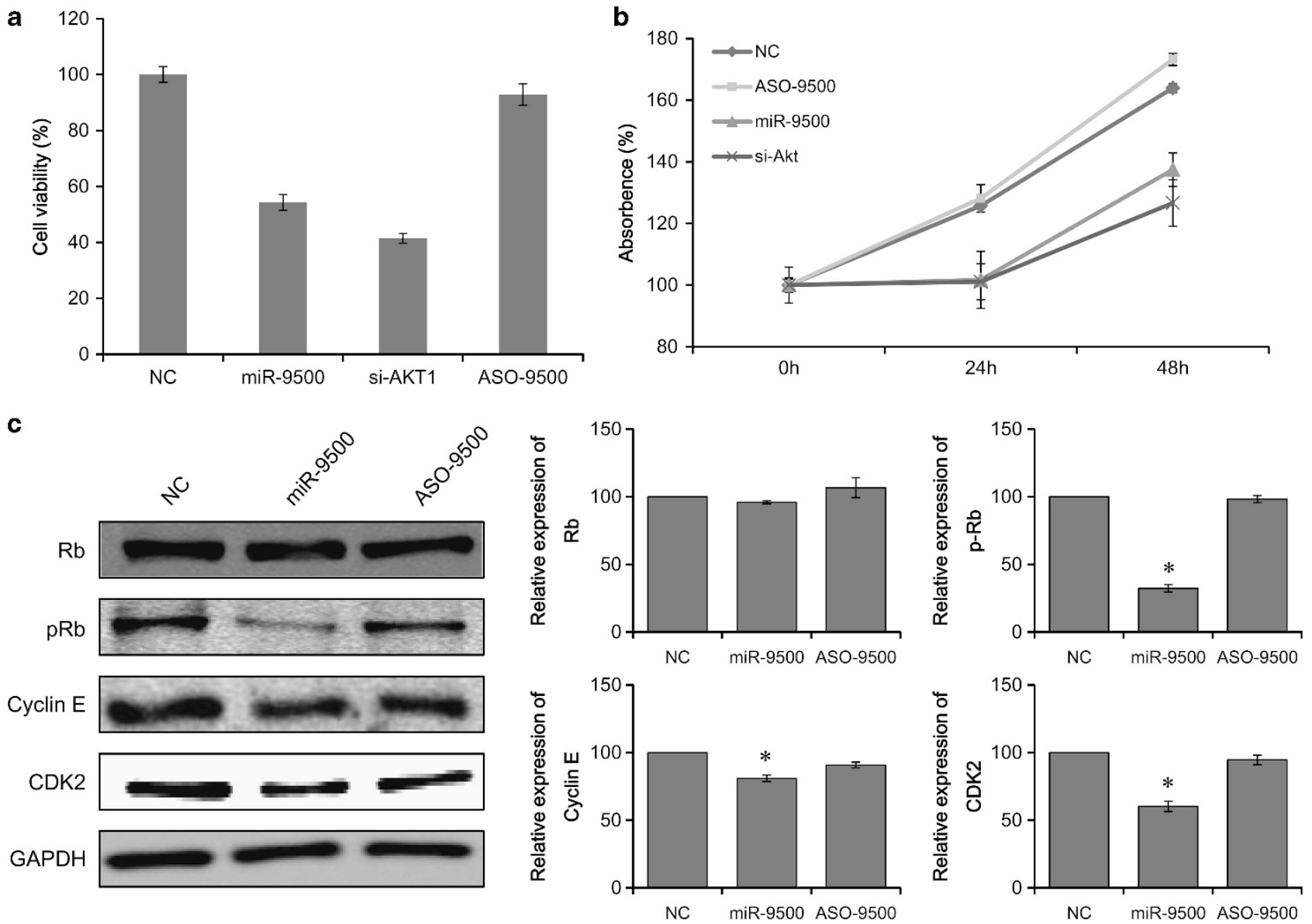

Figure 4 The miR-9500 affects cell proliferation and cell cycle. A549 cells were analyzed after transfection. (a) The proportion of viable cells was assessed using the trypan blue dye exclusion assay. (b) Cell proliferation was determined using an XTT assay. (c) Western blot analysis of the genes downstream of the AKT1 signaling pathway that are associated with the cell cycle. Quantification of the bands was performed using the NIH Image J program, and GAPDH was used as a control. The data are the average of three independent experiments and are shown as the mean \pm S.E.M.; ${ }^{*} P<0.05$ 


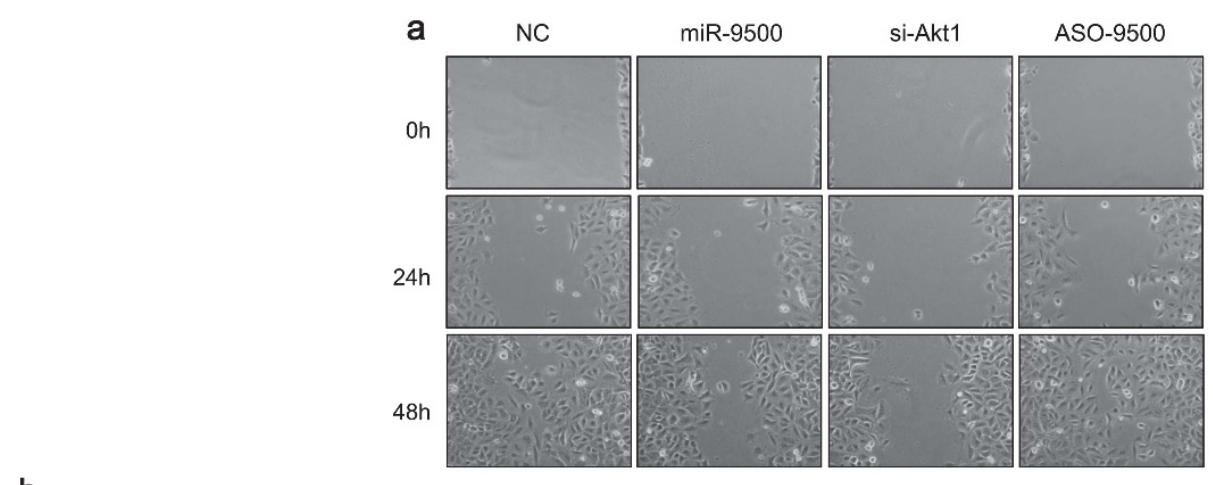

b
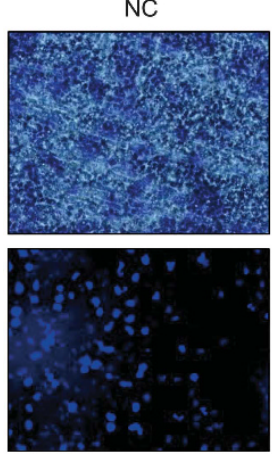

miR-9500
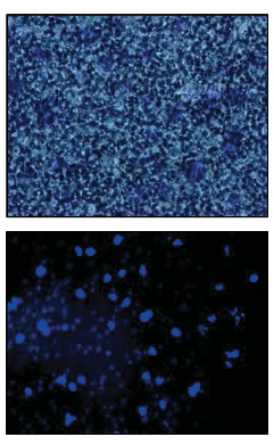

si-Akt1
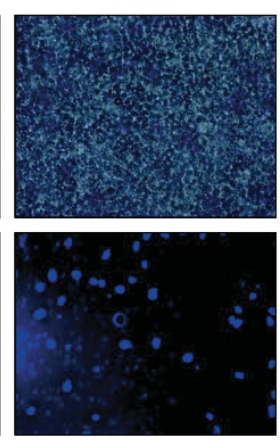

ASO-9500

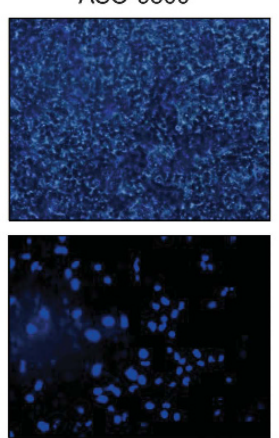

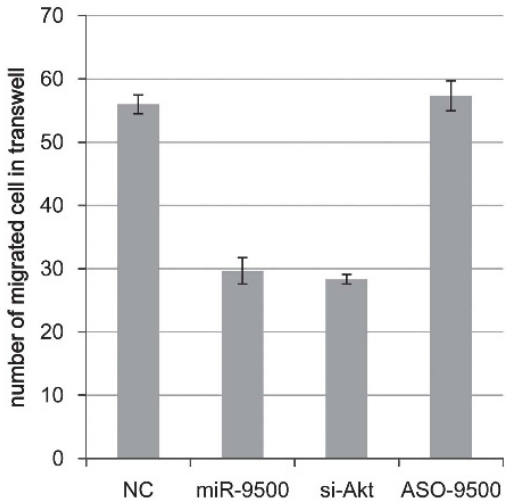

Figure 5 miR-9500 suppresses the migration of A549 cells. (a) A549 cells were transfected and scratched, and images were taken at 0, 24, and 48 h. (b) NC, miR-9500, si-Akt1, and ASO-miR-9500 cells were allowed to migrate through the Transwell insert for $48 \mathrm{~h}$. The cells that migrated through the insert membrane into the lower chamber were stained with $0.2 \%$ crystal violet and Hoechst. The data are the average of three independent experiments

In vivo visualization of firefly luciferase expression regulated by miR-9500. To analyze the miR-9500associated suppression of Fluc (firefly luciferase) activity in nude mice using in vivo imaging, we transfected $\mathrm{NC}$, miR-9500, or ASO-miR-9500 into Fluc-transfected A549 cells, and $1 \times 10^{7}$ transfected cells were harvested and subcutaneously (s.c.) injected into the thighs of nude mice. Fluc activity was detected using an IVIS imaging system for 4 days. The left thigh of the mouse was injected with the nontransfected cells, whereas the right thigh was injected with the NC, miR-9500, or ASO-miR-9500-transfected cells (Figures 6a-c). In this experiment, transfection with miR-9500 significantly repressed Fluc expression compared with transfection with NC or ASO-miR-9500. Next, we determined the therapeutic effect of miR-9500 by measuring the luminescence in the thighs of the nude mice. The miR-9500 mimic suppressed Fluc activity for 2 days; however, Fluc activity then began to increase in the region of interest, similar to the control groups (NC or ASO-miR9500) (Figure 6d). These results suggest that the elevated miR-9500 levels in A549 cells inhibited cell proliferation during the in vivo imaging analysis.

miR-9500 inhibit in vivo tumorigenesis and metastasis. We examined the in vivo tumorigenesis effect of miR-9500 by s.c. injecting A549 cells into nude mice. After 2 weeks, we s.c. injected PBS, NC, miR-9500, or ASO-miR-9500 into nude mice twice a week for 6 weeks. The tumor mass and tumor volume were significantly inhibited by miR-9500 overexpression compared with the control groups (Figures $7 \mathrm{a}$ and b). Histologically stained tumor sections from nude mice showed that there was reduced cell proliferation following miR-9500 overexpression, as shown by Ki67 IHC (Figure 7c, Supplementary Figures 3a and b). To model metastasis, we i.v. injected miR-9500-transfected A549 cells or control cells (PBS, NC, or ASO-miR-9500) into nude mice. The anatomical results indicated a significant decrease in the number of lung metastatic foci ( $>20$-fold), indicating that miR-9500 overexpression in A549 cells strongly repressed metastasis formation in vivo (Figure 8) Together, the in vivo animal assay demonstrated that miR-9500 suppresses tumorigenesis and metastasis.

\section{Discussion}

In this study, we identified a novel miRNA, miR-9500, in lung cancer cells. The miR-9500 is $\sim 70 \mathrm{nt}$ in length and exhibits a secondary folding structure (Figure 1a). The miR-9500 is transcribed from an intergenic region and yields a 19 ntmature sequence. The gene encoding miR-9500 is located on chromosome 3 , and the mature sequence is generated through dicer-dependent processing ${ }^{31}$ (Supplementary Figure 4). In addition, we found that miR-9500 was expressed in almost all cells (Supplementary Figure 5), and the mature sequence of miR-9500 is conserved in other mammals (Figure 1b).

Some studies have indicated that miRNAs have key roles in cancer-associated processes. The let-7a miRNA is 
a

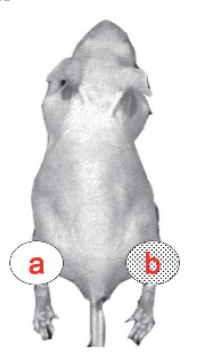

DAY 0
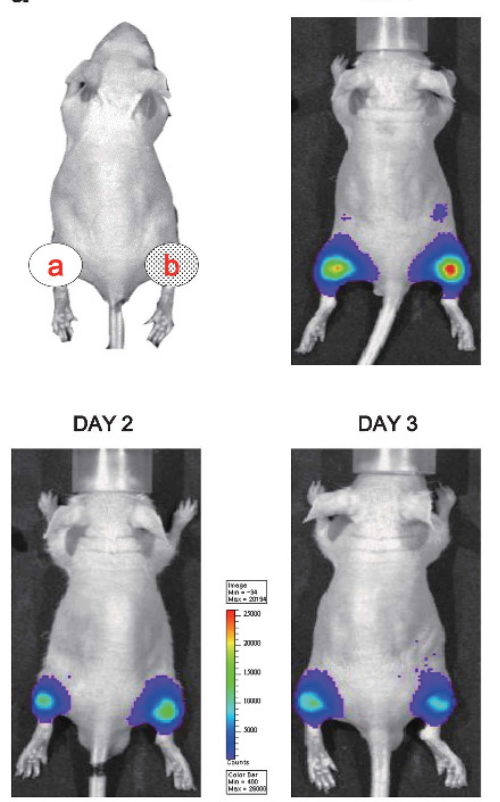

C

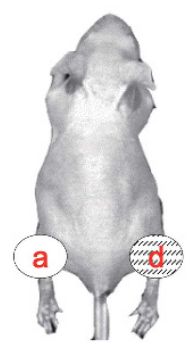

DAY 3
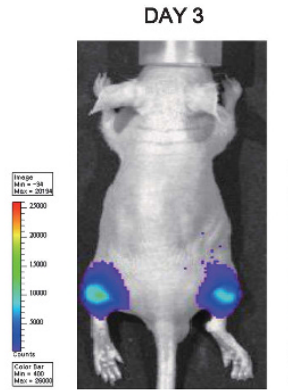

DAY 0
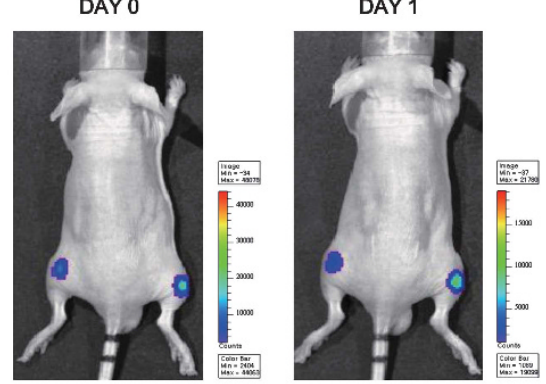

b

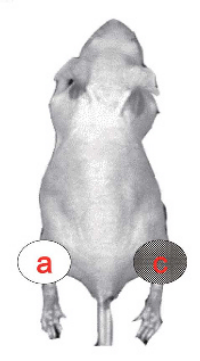

DAY 2

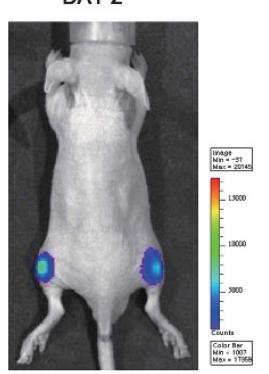

DAY 0

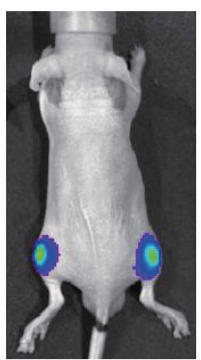

DAY 3

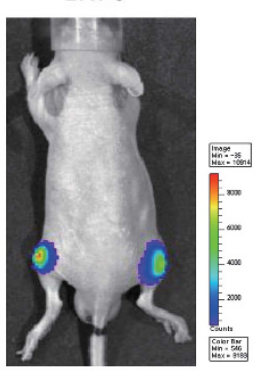

DAY 1

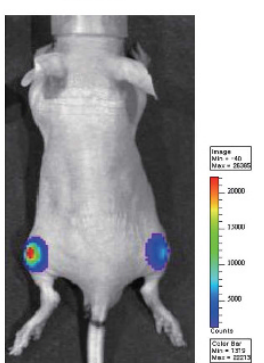

DAY 4

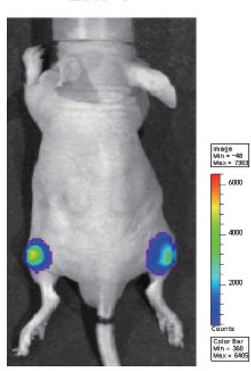

d
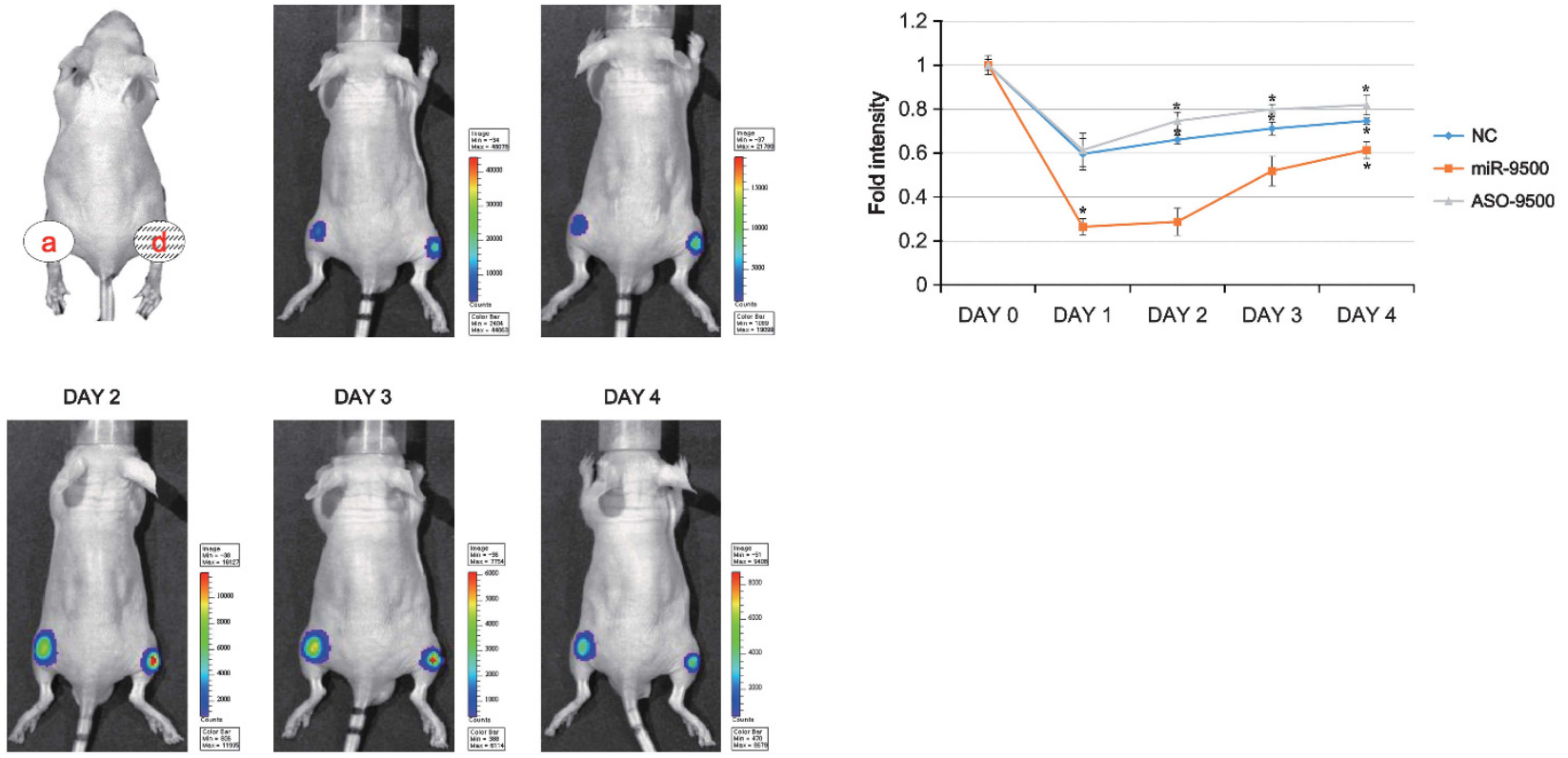

Figure 6 In vivo visualization of Fluc expression regulated by miR-9500. The images show A549 cells that were co-transfected with the Fluc and mimic constructs and subcutaneously injected into nude mice. The left thigh was injected with non-transfected cells $(a)$, whereas the right thigh was injected with NC $(b)$, miR-9500 (c), or ASO-miR-9500 (d)-transfected cells ( $n=3$ mice/group). (a) Comparison of the Fluc repressing activity of the overexpressed NC. (b) Comparison of the Fluc repressing activity of the overexpressed miR-9500. (c) Comparison of the Fluc repressing activity of the overexpressed ASO-miR-9500. (d) Comparisons were made using the ROIs of the bioluminescence images for 4 days. The data are the average of three independent experiments and are shown as the mean \pm S.E.M.; ${ }^{*} P<0.05$

downregulated in lung cancer and suppresses the proliferation of A549 cells. $^{32}$ The expression of miR-193b is downregulated in NSCLC tissues compared with normal tissues and regulates the proliferation, migration, and invasion of NSCLC cells. ${ }^{33}$ We found that miR-9500 was downregulated in various lung-derived cancer cell lines (Figure 2a); additionally, miR-9500 was downregulated in 14 out of 16 paired lung tissue samples (Figure $2 \mathrm{~b}$ ). These results suggest that the downregulation of miR-9500 might be associated with cellular mechanisms related to lung cancer development.

miRNAs regulate their target genes by either targeting the mRNA for degradation or by suppressing protein expression. ${ }^{34}$ Because miR-9500 was downregulated in lung cancer cell lines and tissues, we examined the upregulated genes in lung cancer to predict the target genes using the EMBL databases. Next, we selected the putative target genes 
that are involved in cell proliferation and migration. Some studies have reported that genes related to cell proliferation and migration may have potential relevance in cancer therapy. ${ }^{33}$ Novel miRNAs cannot be examined with target gene search programs, such as TargetScan. Thus, we identified perfect base pairing between the $5^{\prime}$ end of the novel miR-9500 and the target site of the predicted target genes. ${ }^{35}$ Finally, we selected the Akt1 gene as a putative target gene. The Akt serine/threonine kinase family contains three members, Akt1, Akt2, and Akt3, that have roles in cell growth and tumorigenesis. ${ }^{36,37}$

We identified AKT1 expression as being upregulated in NSCLC using a web program (http://www.ebi.ac.uk/gxa/ E-MTAB-37), and a previous study reported AKT activation in NSCLCs. ${ }^{38}$ We constructed a vector containing the $3^{\prime}-U T R$ of the Akt1 gene, which included the sequence from 955 to $961 \mathrm{nt}$, and confirmed that the Akt1 gene was regulated by miR-9500 using a luciferase reporter assay (Figure 3a). Although the mRNA levels of Akt1 were not affected by miR-9500, the protein expression levels of AKT1 and p-AKT were decreased following miR-9500 overexpression (Figures $3 \mathrm{~b}$ and $\mathrm{c}$ ). These data indicated that miR-9500 negatively regulates Akt 1 expression by binding to the $3^{\prime}-$ UTR of the Akt1 gene.

Akt1 expression is associated with cell survival, growth, and migration in cancer, ${ }^{26,27}$ and a decrease in p-AKT expression levels due to Akt1 knockdown considerably affects cell proliferation. ${ }^{29}$ We found that the proliferation of the A549 cells was inhibited by the overexpression of miR-9500 compared with the overexpression of the NC (Figures $4 \mathrm{a}$ and $b$ ). The PI3K/Akt signaling pathway is involved in cell proliferation and survival in lung cancer. ${ }^{39}$ Likewise, Akt1 is known to regulate cell proliferation but also is involved in cellular apoptosis. ${ }^{40}$ However, miR-9500 overexpression did not result in signal transduction leading to apoptosis or survival (Supplementary Figure 6). In this study, we focused on cell proliferation and examined the effects of miR-9500 on the genes downstream of the PI3K/Akt signaling pathway. The protein levels of cyclin E and CDK2 were modulated by the downregulation of AKT1, whereas the protein levels of $R b$ were slightly decreased (Figure 4c). Some studies have shown that the inhibition of $\mathrm{p}-\mathrm{AKT}$ and AKT promotes the downregulation of cyclin $\mathrm{E}$. ${ }^{41}$ The downregulation of cell cycle regulatory proteins, such as $\mathrm{Rb}$, cyclin $\mathrm{E}$, and $\mathrm{CDK} 2$, induces an S-phase cell cycle arrest. ${ }^{42}$ Actually, the miR-9500transfected A549 cells had an increased number of cells in the G1 phase, as well as a reduced number of S and G2/M phase cells, according to flow cytometry analysis.

We found that AKT1 regulates cancer development processes, including motility and migration. ${ }^{33}$ Therefore, these data suggest that miR-9500 inhibits cell proliferation by targeting Akt1 in lung cancer cells. In addition, Akt1 is known to be involved in cell migration. ${ }^{27}$ Thus, our data show that miR-9500 modulates cell motility and migration in A549 cells by targeting the Akt1 gene (Figures $5 \mathrm{a}$ and b). In vivo bioluminescence images of Fluc activity demonstrated the same result; miR-9500 suppressed Fluc expression compared with treatment with NC and ASO-miR-9500. Cells were transiently co-transfected with miR-9500 and the Fluc vector and were then injected into the right thigh of nude mice, and these cells exhibited a significant decrease in Fluc expression (Figure 6d). However, the Fluc vector did not contain a binding site for miR-9500. Thus, miR-9500 did not directly inhibit Fluc activation; however, Fluc downregulation was a consequence of the suppression of cell proliferation by miR-9500 expression. ${ }^{43,44}$ In addition, miR-9500 expression repressed tumorigenesis and metastasis in vivo. As shown in Figure 7, mice that were s.c. injected with miR-9500 exhibited decreased tumorigenesis compared with the NC- and ASO-miR-9500injected mice.

During tumorigenesis, Akt1 has important roles in tumor progression by regulating gene expression, such as the genes downstream of the Akt signaling pathway. The miR-302-367 cluster represses tumorigenesis in cervical carcinoma by targeting Akt1. ${ }^{45}$ In addition, the miR-133b family indirectly upregulates the Akt1 pathway during tumorigenesis. ${ }^{46}$ The miR-9500 also suppresses metastatic activity compared with the NC or ASO-miR-9500 (Figure 8). Akt1 activation and expression results in the progression of tumorigenesis, as well as metastasis, in various cancers. ${ }^{47}$ This result indicates that miR-9500 directly inhibits cell proliferation and metastasis in vivo.

In conclusion, we identified the novel miRNA, miR-9500, which was downregulated in lung cancer cells and paired lung cancer tissue samples, as having a role in lung cancer. Moreover, miR-9500 directly regulated the protein expression of AKT1 by targeting the $3^{\prime}$-UTR of the Akt1 mRNA. The decreased expression of AKT1 following treatment with miR-9500 resulted in the inhibition of cell proliferation and migration in vitro and in vivo. These findings indicate that miR-9500 has a role in the development of lung cancer and may provide a novel therapeutic target for lung cancer therapy.

\section{Materials and Methods}

Cell lines and tissue samples. The A549 (lung adenocarcinoma), HCC-1588 (lung squamous carcinoma), and NCl-H596 (lung adenosquamous carcinoma) human lung cancer cell lines and the WI-38VA-13 cell line (SV-40transformed human lung epithelial cell line) were maintained in RPMI-1640 medium (Welgene, Deagu, Korea), whereas WI-38 cells (human diploid lung normal fibroblast cell line) were maintained in Eagle's minimum essential medium (Welgene). All media were supplemented with $10 \%$ fetal bovine serum (Welgene) and $1 \%$ antibiotics $(100 \mathrm{U} / \mathrm{ml}$ penicillin and $100 \mu \mathrm{g} / \mathrm{ml}$ streptomycin, Welgene). All cell lines were incubated at $37^{\circ} \mathrm{C}$ in a $5 \% \mathrm{CO}_{2}$ atmosphere. The human cell lines were purchased from the American Type Culture Collection (ATCC; Manassas, VA, USA) and the Korean cell line bank (KCLB; Seoul, Korea). All tissue samples were obtained from the Korea Lung Tissue Bank, which is supported by the Korea Science and Engineering Foundation at the Ministry of Science and Technology (Supplementary Table 1).

Total RNA isolation and novel miRNA cloning. Total RNA was extracted from various cell lines and lung tissue samples using the TRIzol reagent (Ambion, Foster City, CA, USA), according to the manufacturer's protocol. Before cloning the novel miRNAs, total RNAs smaller than $200 \mathrm{nt}$ were isolated from the $\mathrm{NCl}-\mathrm{H} 596$ lung cancer cell line using the mirVana RNA isolation kit (Ambion). The miRNAs were cloned into vectors using the ${ }^{\text {Dyna }}$ Express miRNA Cloning Kit (BioDynamics Laboratory Inc., Tokyo, Japan), according to the manufacturer's instructions with some modifications. ${ }^{48,49}$

Transfection and mimics. The cell transfections were performed using Lipofectamine 2000 (Invitrogen, Carlsbad, CA, USA), according to the manufacturer's protocol. The media was changed $4-6 \mathrm{~h}$ after the transfection without washing with PBS. The miRNA mimics (miR-9500; sense $5^{\prime}$-AA GGGAAGAUGGUGACCACUU- $3^{\prime}$ and antisense $5^{\prime}$-GUGGUCACCAUCUUCCC UUUU- $3^{\prime}$ ), miR-9500 inhibitors (antisense oligonucleotide (ASO)-miR-9500; 5'-GU 
a

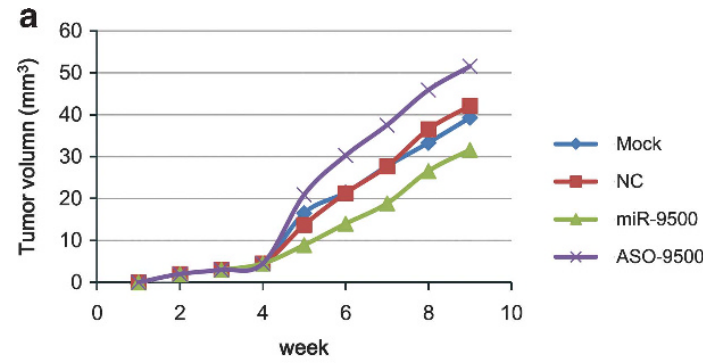

b

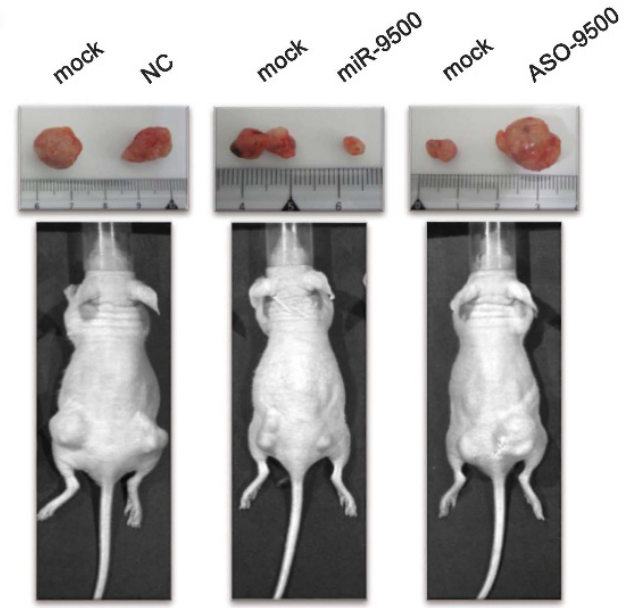

c

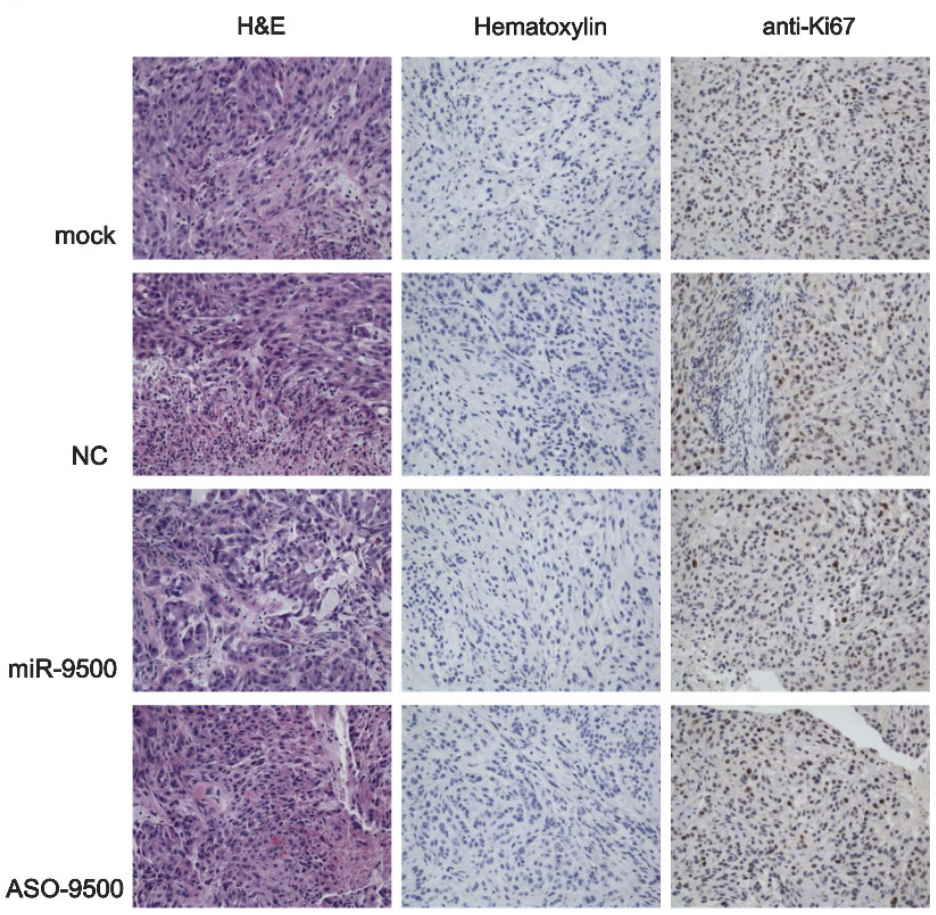

Figure 7 The miR-9500 suppresses A549 tumor formation by inhibiting cell proliferation. A549 cells were injected s.c. into either posterior flank of the same nude mouse. After 2 weeks, the left flank was injected with PBS, whereas the right flank was injected with either the NC, miR-9500, or ASO-miR-9500 mimics twice a week ( $n=3$ mice/ group) (a) Tumor size was measured every week. (b) After 6 weeks, the mice were photographed and euthanized. (c) H\&E staining and Ki67 IHC in the tumors formed by A549 cells that were directly injected s.c. with miR-9500, NC, ASO-miR-9500, or PBS

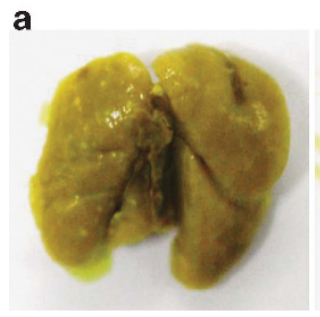

mock

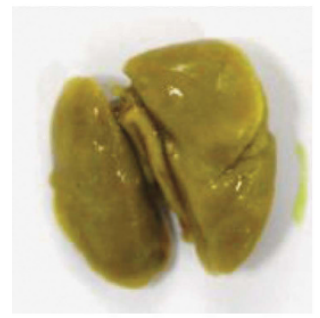

miR-9500

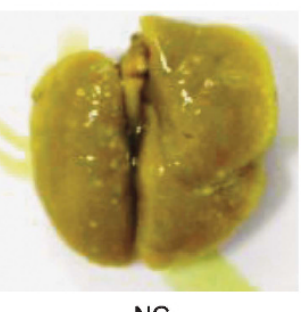

NC

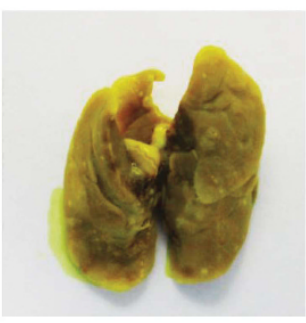

ASO-9500

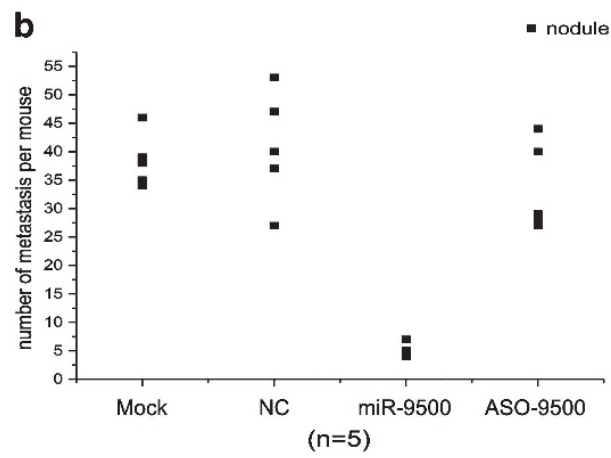

Figure 8 The miR-9500 treatment via tail vein injection inhibits metastasis of A549 cells. PBS or miR-9500, NC, or ASO-miR-9500-transfected cells were i.v. injected into mice every week ( $n=5$ mice/group). (a) A representative lung 4 weeks after i.v. injection of the transfected A549 cells. (b) Quantification of the visually observable metastatic foci on the lung surface 4 weeks after i.v. injection of the transfected A549 cells

GGUCACCAUCUUCCCUU-3'), siRNAs (si-AKT1; sense $5^{\prime}$-UUCACAAUAGC CACGUCGCUU- $3^{\prime}$ and antisense $5^{\prime}$-GCGACGUGGCUAUUGUGAAUU- $3^{\prime}$ ), and NC (sense $5^{\prime}$-ACGUGACACGUUCGGAGAAUU-3' and antisense $5^{\prime}$-AAUUCUCC GAACGUGUCACGU-3', non-homologous with human genome sequences) were designed and purchased from Genolution Pharmaceuticals, Inc. (Seoul,
Korea). The dose-dependent effect of miR-9500 was determined using real-time qRT-PCR, and the others were confirmed by its standards (Supplementary Figure 7).

TaqMan miRNA assays and real-time qRT-PCR analysis. TaqMan miRNA assays (Applied Biosystems, Foster City, CA, USA) were conducted as 
previously described ${ }^{50}$ using miRNA-specific primers. Using this method, we identified the miRNA expression pattern for the normal group and the abnormal group. Data analysis was performed using the $2^{-\Delta \Delta C t}$ method. Real-time PCR was conducted using a Quanti Tect SYBR Green PCR kit (QIAGEN, Hilden, Germany) and a Real-Time PCR Detection System (Bio-Rad, Berkeley, CA, USA). The following primer sequences were used: Akt1 forward $5^{\prime}$-TCCCGAGGC CAAGTCCTT- $3^{\prime}$ and reverse $5^{\prime}$-CCGCCAAGCCTCTGCTT-3' and GAPDH forward $5^{\prime}$-TGTGCACCACCAACTGCTTAGC- $3^{\prime}$ and reverse $5^{\prime}$-GGCATGGA CTGTGGTCATGAG-3'. The data were representative of three independent experiments performed on different days.

Dual luciferase reporter assay. Approximately $400 \mathrm{nt}$ of the $3^{\prime}$-UTR of the Akt1 gene containing the predicted miR-9500-binding site was inserted into the luciferase reporter vector, pGL4. The Akt1-3'-UTR-mutant construct was generated using the Muta Direct Site-Directed Mutagenesis kit (iNtRON, Seoungnam, Korea). Next, $200 \mathrm{ng}$ of plasmid and $100 \mathrm{nmol}$ of either miR-9500 or NC were co-transfected into A549 cells for $24 \mathrm{~h}$. As a control, the pGL3-control vector was co-transfected for normalization. Luciferase activity was measured using the Dual-Luciferase Reporter Assay System kit (Promega, Madison, WI, USA), and luminescence intensity was measured using an analyzer VICTOR ${ }^{3}$ (PerkinElmer, Foster City, CA, USA). The data were representative of three independent experiments performed on different days.

Western blot analysis. Proteins were extracted in RIPA cell lysis buffer (Elpis, Daejeon, Korea). The proteins were fractionated by sodium dodecyl sulfate (SDS)-polyacrylamide gel electrophoresis and then transferred onto a polyvinylidene fluoride membrane (pore size; $0.45 \mu \mathrm{m}$; GE Healthcare, Piscataway, $\mathrm{NJ}$, USA). The membranes were blocked for $40 \mathrm{~min}$ in $5 \%$ skim milk (BD Biosciences, San Jose, CA, USA) in TBS-T buffer at room temperature and were washed three times with TBS-T. The membranes were probed with AKT1, p-AKT (1:1000 dilution in 5\% skim milk, Cell Signaling, Danvers, MA, USA), Rb, p-Rb, cyclin E, CDK2 (1:1000 dilution in 5\% skim milk, Santa Cruz Biotechnology, Santa Cruz, CA, USA), or GAPDH (1:5000 dilution in 5\% skim milk, glyceraldehyde-3-phosphate dehydrogenase; $A B$ Frontier, Seoul, Korea) primary antibodies, and the membranes were then incubated at $4{ }^{\circ} \mathrm{C}$ with the appropriate secondary antibodies (1:5000 dilution in 5\% skim milk, whole-antibodies purchased from Santa Cruz Biotechnology). GAPDH was used as an internal control. Quantification of the bands was performed using the $\mathrm{NIH}$ Image $\mathrm{J}$ program, and the data are representative of three independent experiments performed on different days.

Trypan blue staining. Cell viability was assessed using the trypan blue (Lonza, Basel, Switzerland) exclusion method. The A549 cells were seeded in 24-well culture plates at a density of $3 \times 10^{5}$ cells per well, and the cells were then transfected with NC, miR-9500, si-Akt1, or the ASO-miR-9500. Each cell suspension was mixed with an equal volume of $0.4 \%$ trypan blue solution, and the living cells were quantified using a hemocytometer. The cells were also counted using a microscope. The data are representative of three independent experiments performed on different days.

XTT proliferation assay. A549 cells were plated at a density of $1 \times 10^{4}$ cells per well in 96-well culture plates. The miR-9500 miRNA, NC, si-Akt1, and the ASO-miR-9500 were then transfected into the cells. The proliferation rates of the cells were determined using $50 \mu$ l XTT test solution; the solution was composed of $5 \mathrm{ml}$ of XTT-labeled reagent and $100 \mu \mathrm{l}$ of electron coupling reagent. Cell proliferation was assessed at 0,24 , and $48 \mathrm{~h}$ after transfection using the Cell Proliferation Kit (XTT, Roche, Mannheim, Germany). The absorbance was recorded at a wavelength of $490 \mathrm{~nm}$, which was determined using an ELISA reader. The data are representative of three independent experiments performed on different days.

Wound healing assay. A549 cells were seeded in 6-well culture plates and were transfected with NC, miR-9500, si-Akt1, or ASO-miR-9500. Next, a line was scratched into the cell monolayer using a sterile pipette tip, and the cells were further incubated. The wound was photographed using a microscope. The data are representative of three independent experiments performed on different days.

Transwell migration assay. The migration of A549 cells was measured using the Transwell system (Corning Inc., Corning, NY, USA). Transwell inserts with $8 \mathrm{~mm}$ pores were coated with $0.1 \%$ gelatin (Sigma, St. Louis, MO, USA). After the A549 cells were transfected, $1 \times 10^{4}$ of A549 cells were seeded in $0.2 \mathrm{ml}$ of serum free media; $0.5 \mathrm{ml}$ of media containing $10 \%$ serum was placed in the lower wells. After $24 \mathrm{~h}$, the cells that had migrated toward the lower surface were fixed in $95 \%$ ethanol, stained with $0.2 \%$ crystal violet (Sigma) and Hoechst solution (Invitrogen) for $30 \mathrm{~min}$ and then washed with PBS. The images were recorded using a microscope. The data are representative of three independent experiments performed on different days.

In vivo Fluc visualization of miR-9500 in nude mice. All animals used in the in vivo experiments were housed under specific pathogen-free conditions, and the experiments were approved by the institutional animal care and use committee of CHA University. For in vivo imaging, miR-9500 and Fluc were co-transfected into A549 cells. Then, $1 \times 10^{7}$ cells were injected s.c. into both thighs of the nude mice (male BALB/c, 4 weeks old). The detailed protocol is described in Kim et al. ${ }^{43}$

Tumorigenesis and metastasis experiments. Male nude mice (male $B A L B / c, 6$ weeks old) were used in the xenograft experiments and for the metastasis experiments. Each mouse experiment was repeated three times. A total of $5 \times 10^{6}$ of A549 cells were injected s.c. into a 6-week-old nude mouse. After 2 weeks, PBS, NC, miR-9500, or ASO-miR-9500 were s.c. injected twice a week. The tumor width and length were measured every week. Every 2 weeks, 3 mice from each group were euthanized, for a total of 6 weeks. The tumor tissue was embedded in paraffin, and the sections were stained with hematoxylin and eosin (H\&E); Ki67 immunohistochemistry was performed using standard procedures. For the metastasis model, $2 \times 10^{6}$ of A549 cells were injected into each mouse via tail vein injection, and PBS, NC, miR-9500, or ASO-miR-9500 were injected every week via tail vein injection. Three mice from each group were euthanized 2 or 3 weeks after the injection of the A549 cells to monitor the appearance of metastases. All remaining mice were euthanized 4 weeks after the injection of A549 cells. To clearly observe the metastasis nodules, the lungs were fixed in Bouin's solution (Sigma). The observable metastatic foci on lung surface were counted.

Immunostaining. Xenograft tumors that formed from A549 cells after 4, 6, and 8 weeks were dissected out, fixed in $4 \%$ PFA, processed and embedded in paraffin. Immunohistochemistry was performed on the paraffin sections mounted on slides. The sections were stained with H\&E and were immunostained with an anti-Ki67 antibody (Santa Cruz Biotechnology).

Statistical analysis. The data are presented as the mean \pm S.E.M. from at least three independent experiments. The significant differences were analyzed using the Student's $t$-test. $P$-values $<0.05$ were considered statistically significant.

\section{Conflict of Interest}

The authors declare no conflict of interest.

Acknowledgements. This research was supported by Basic Science Research Program (2012007471) and Stem Cell Research Program (2006-2004127) through the National Research Foundation of Korea (NRF) funded by the Ministry of Education, Science and Technology.

1. Bartel DP. MicroRNAs: genomics, biogenesis, mechanism, and function. Cell 2004; 116: 281-297.

2. Lewis BP, Burge CB, Bartel DP. Conserved seed pairing, often flanked by adenosines, indicates that thousands of human genes are microRNA targets. Cell 2005; 120: 15-20.

3. Rodriguez A, Griffiths-Jones S, Ashurst JL, Bradley A. Identification of mammalian microRNA host genes and transcription units. Genome Res 2004; 14: 1902-1910.

4. Lee Y, Jeon K, Lee JT, Kim S, Kim VN. MicroRNA maturation: stepwise processing and subcellular localization. EMBO J 2002; 21: 4663-4670.

5. Zeng $Y, Y i$ R, Cullen BR. MicroRNAs and small interfering RNAs can inhibit mRNA expression by similar mechanisms. Proc Natl Acad Sci USA 2003; 100: 9779-9784.

6. Lee Y, Kim M, Han J, Yeom KH, Lee S, Baek SH et al. MicroRNA genes are transcribed by RNA polymerase II. EMBO J 2004; 23: 4051-4060.

7. Shenouda SK, Alahari SK. MicroRNA function in cancer: oncogene or a tumor suppressor? Cancer Metastasis Rev 2009; 28: 369-378. 
8. Diederichs S, Haber DA. Dual role for argonautes in microRNA processing and posttranscriptional regulation of microRNA expression. Cell 2007; 131: 1097-1108.

9. Hammond SM, Bernstein E, Beach D, Hannon GJ. An RNA-directed nuclease mediates post-transcriptional gene silencing in Drosophila cells. Nature 2000; 404: 293-296.

10. Martinez J, Patkaniowska A, Urlaub H, Luhrmann R, Tuschl T. Single-stranded antisense siRNAs guide target RNA cleavage in RNAi. Cell 2002; 110: 563-574.

11. Xiong J, Du Q, Liang Z. Tumor-suppressive microRNA-22 inhibits the transcription of E-box-containing c-Myc target genes by silencing c-Myc binding protein. Oncogene 2010; 29: $4980-4988$

12. Esquela-Kerscher A, Slack FJ. Oncomirs-microRNAs with a role in cancer. Nat Rev Cancer 2006; 6: 259-269.

13. Jemal A, Siegel R, Xu J, Ward E. Cancer statistics. CA Cancer J Clin 2010; 60: 277-300.

14. Schiller JH, Harrington D, Belani CP, Langer C, Sandler A, Krook J et al. Comparison of four chemotherapy regimens for advanced non-small-cell lung cancer. N Engl J Med 2002; 346: 92-98.

15. Wu X, Piper-Hunter MG, Crawford M, Nuovo GJ, Marsh CB, Otterson GA et al. MicroRNAs in the pathogenesis of lung cancer. $J$ Thorac Oncol 2009; 4: 1028-1034.

16. Croce $\mathrm{CM}$. Causes and consequences of microRNA dysregulation in cancer. Nat Rev Genet 2009; 10: 704-714.

17. Takamizawa J, Konishi H, Yanagisawa K, Tomida S, Osada H, Endoh $\mathrm{H}$ et al. Reduced expression of the let-7 microRNAs in human lung cancers in association with shortened postoperative survival. Cancer Res 2004; 64: 3753-3756.

18. Bandi N, Zbinden S, Gugger M, Arnold M, Kocher V, Hasan L et al. miR-15a and miR-16 are implicated in cell cycle regulation in a Rb-dependent manner and are frequently deleted or down-regulated in non-small cell lung cancer. Cancer Res 2009; 69: 5553-5559.

19. Hayashita $Y$, Osada H, Tatematsu Y, Yamada H, Yanagisawa K, Tomida S et al. A polycistronic microRNA cluster, miR-17-92, is overexpressed in human lung cancers and enhances cell proliferation. Cancer Res 2005; 65: 9628-9632.

20. Takahashi Y, Forrest AR, Maeno E, Hashimoto T, Daub CO, Yasuda J. MiR-107 and MiR-185 can induce cell cycle arrest in human non small cell lung cancer cell lines. PLoS One 2009; 4: e6677.

21. Altomare DA, Testa JR. Perturbations of the AKT signaling pathway in human cancer Oncogene 2005; 24: 7455-7464.

22. Vivanco I, Sawyers CL. The phosphatidylinositol 3-Kinase AKT pathway in human cancer Nat Rev Cancer 2002; 2: 489-501.

23. Datta SR, Brunet A, Greenberg ME. Cellular survival: a play in three Akts. Genes Dev 1999; 13: 2905-2927.

24. Vanhaesebroeck B, Waterfield MD. Signaling by distinct classes of phosphoinositide 3-kinases. Exp Cell Res 1999; 253: 239-254.

25. Wendel HG, De Stanchina E, Fridman JS, Malina A, Ray S, Kogan S et al Survival signalling by Akt and elF4E in oncogenesis and cancer therapy. Nature 2004; 428: 332-337.

26. Dey JH, Bianchi F, Voshol J, Bonenfant D, Oakeley EJ, Hynes NE. Targeting fibroblast growth factor receptors blocks PI3K/AKT signaling, induces apoptosis, and impairs mammary tumor outgrowth and metastasis. Cancer Res 2010; 70: 4151-4162.

27. Hollier BG, Kricker JA, Van Lonkhuyzen DR, Leavesley DI, Upton Z Substrate-bound insulin-like growth factor (IGF)-I-IGF binding protein-vitronectin-stimulated breast cell migration is enhanced by coactivation of the phosphatidylinositide 3-Kinase/AKT pathway by alphav-integrins and the IGF-I receptor. Endocrinology 2008; 149: 1075-1090.

28. Ma J, Sawai H, Ochi N, Matsuo Y, Xu D, Yasuda A et al. PTEN regulates angiogenesis through PI3K/Akt/VEGF signaling pathway in human pancreatic cancer cells. Mol Cell Biochem 2009; 331: 161-171.

29. Zhou W, Fu XQ, Liu J, Yu HG. RNAi knockdown of the Akt1 gene increases the chemosensitivity of gastric cancer cells to cisplatin both in vitro and in vivo. Regul Pept 2012; 176: 13-21.
30. Blanco-Aparicio C., Cañamero M, Cecilia Y, Pequeño B, Renner O, Ferrer I et al. Exploring the gain of function contribution of AKT to mammary tumorigenesis in mouse models. PLoS One 2010; 5: e9305.

31. Schmitter D., Filkowski J, Sewer A, Pillai RS, Oakeley EJ, Zavolan M et al. Effects of Dicer and Argonaute down-regulation on mRNA levels in human HEK293 cells. Nucleic Acids Res 2006; 34: 4801-4815.

32. He X., Duan C, Chen J, Ou-Yang X, Zhang Z, Li C et al. Let-7a elevates p21(WAF1) levels by targeting of NIRF and suppresses the growth of A549 lung cancer cells. FEBS Lett 2009; 583: 3501-3507.

33. Hu H, Li S, Liu J, Ni B. MicroRNA-193b modulates proliferation, migration, and invasion of non-small cell lung cancer cells. Acta Biochim Biophys Sin (Shanghai) 2012; 44: 424-430.

34. Garzon R, Marcucci G, Croce CM. Targeting microRNAs in cancer: rationale, strategies and challenges. Nat Rev Drug Discov 2010; 9: 775-789.

35. Rajewsky N. microRNA target predictions in animals. Nat Genet 2006; 38: S8-13.

36. Brazil DP, Yang ZZ, Hemmings BA. Advances in protein kinase B signalling: AKTion on multiple fronts. Trends Biochem Sci 2004; 29: 233-242.

37. Manning BD, Cantley LC. AKT/PKB signaling: navigating downstream. Cell 2007; 129: $1261-1274$

38. Scrima M, De Marco C, Fabiani F, Franco R, Pirozzi G, Rocco G et al. Signaling networks associated with AKT activation in non-small cell lung cancer (NSCLC): new insights on the role of phosphatydil-inositol-3 kinase. PLoS One 2012; 7: e30427.

39. Xu CX, Jin H, Shin JY, Kim JE, Cho MH. Roles of protein kinase B/Akt in lung cancer. Front Biosci (Elite Ed) 2010; 2: 1472-1484.

40. Lee MW et al. Roles of AKT1 and AKT2 in non-small cell lung cancer cell survival, growth, and migration. Cancer Sci 2011; 102: 1822-1828.

41. Yu YH, Kim DS, Lee JH, Lee BS, Lee SH, Jung HL et al. Ganoderma tsugae Induces S Phase Arrest and Apoptosis in Doxorubicin-Resistant Lung Adenocarcinoma H23/0.3 Cells via Modulation of the PI3K/Akt Signaling Pathway. Evid Based Complement Alternat Med 2012; 2012: 371286.

42. Jeong JB, Hong SC, Jeong HJ, Koo JS. Arctigenin induces cell cycle arrest by blocking the phosphorylation of $\mathrm{Rb}$ via the modulation of cell cycle regulatory proteins in human gastric cancer cells. Int Immunopharmacol 2011; 11: 1573-1577.

43. Kim JK, Choi KJ, Lee M, Jo MH, Kim S. Molecular imaging of a cancer-targeting theragnostics probe using a nucleolin aptamer- and microRNA-221 molecular beaconconjugated nanoparticle. Biomaterials 2012; 33: 207-217.

44. Ko HY, Lee DS, Kim S. Noninvasive imaging of microRNA124a-mediated repression of the chromosome 14 ORF 24 gene during neurogenesis. FEBS J 2009; 276: 4854-4865.

45. Cai N, Wang YD, Zheng PS. The microRNA-302-367 cluster suppresses the proliferation of cervical carcinoma cells through the novel target AKT1. RNA 2013; 19: 85-95.

46. Qin W, Dong P, Ma C, Mitchelson K, Deng T, Zhang L et al. MicroRNA-133b is a key promoter of cervical carcinoma development through the activation of the ERK and AKT1 pathways. Oncogene 2012; 31: 4067-4075.

47. Bjerke GA, Yang C-S, Frierson HF, Paschal BM, Wotton D. Activation of Akt signaling in prostate induces a TGF $\beta$-mediated restraint on cancer progression and metastasis. Oncogene 2013; e-pub ahead of print 2 September 2013; doi:10.1038/ onc.2013.342.

48. Rao JR, Nelson D, Moore JE, Millar BC, Goldsmith CE, Rendall J et al. Non-coding small (micro) RNAs of Pseudomonas aeruginosa isolated from clinical isolates from adult patients with cystic fibrosis. Br J Biomed Sci 2010; 67: 126-132.

49. Yoo JK, Kim J, Choi SJ, Noh HM, Kwon YD, Yoo H et al. Discovery and characterization of novel microRNAs during endothelial differentiation of human embryonic stem cells. Stem Cells Dev 2012; 21: 2049-2057.

50. Chen C, Ridzon DA, Broomer AJ, Zhou Z, Lee DH, Nguyen JT et al. Real-time quantification of microRNAs by stem-loop RT-PCR. Nucleic Acids Res 2005; 33: e179.

\section{Supplementary Information accompanies this paper on Cell Death and Differentiation website (http://www.nature.com/cdd)}

